\title{
Psychological Resilience and Positivity as Predictors of Self-Efficacy
}

\section{Tuğba Yılmaz Bingöl ${ }^{1} \rtimes$ Meryem Vural Batık ${ }^{2}$ Rumeysa Hoşoğlu Aynur Firıncı Kodaz ${ }^{4}$}

'Fatih Sultan Mehmet Vakıf Üniversitesi, Faculty of Education, İstanbul, Türkiye Email:tbingol@fsm.edu.trTel:05055227682

'Ondokuz Mayıs Üniversitesi, Faculty of Education, Samsun, Türkiye

Email:meryem.vural@omu.edu.trTel:0553 3290776

${ }^{3}$ Kapadokya Üniversitesi, School of Health Sciences, Nevşehir, Türkiye

Email: rumeysa.hosoglu@,hapadohya.edu.trTel: 05068449782

${ }^{~}$ Hatice Gani Erverdi Middle School, Nilïfer, Bursa, Türkive

Email:aynurfirinci@gmail.com Tel:+4915147722606

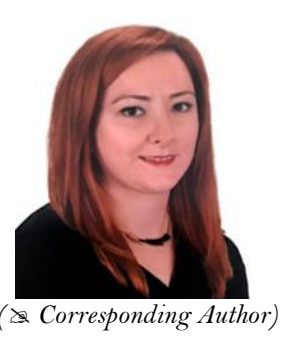

Abstract

The purpose of this study is to examine the relationship between self-efficacy, a concept that has an important role in human life, and different demographic variables and the predictive roles of psychological resilience and positivity on self- efficacy. The research was carried out with 844 students studying at four different universities in provinces of Istanbul, Samsun, Bursa and Ankara in Turkey. Participants completed the questionnaire packet including the General SelfEfficacy Scale, the Brief Psychological Resilience Scale, the Positivity Scale and a personal information form. The analyses of the data were carried out via SPSS 20. The results showed that the female subjects tended to report lower self-efficacy than the males and participants living in cities and high income participants reported higher self-efficacy than the participants living in villages or small towns and the low income participants. Additionally, it may be stated that the participants who perceived their parents as democratic, negligent and protective reported higher levels of self-efficacy than those who perceived their parents as authoritarian. The results also indicated a moderate positive relationship between psychological resilience and self-efficacy, and a low positive correlation between self-efficacy and positivity. Psychological resilience and positivity were found to be important predictors of self-efficacy.

Keywords: Self-Efficacy, Psychological resilience, Positivity, Positive psychology, Predictors, Parental attitudes. JEL Classification: I29

Citation | Tuğba Yılmaz Bingöl; Meryem Vural Batık; Rumeysa Hoşoğlu; Aynur Fırıncı Kodaz (2019). Psychological Resilience and Positivity as Predictors of Self-Efficacy. Asian Journal of Education and Training, 5(1): 63-69.

History:

Received: 8 October 2018

Revised: 15 November 2018

Accepted: 21 December 2018

Published: 3 January 2019

Licensed: This work is licensed under a Creative Commons Attribution 3.0 License (cc) IE

Publisher: Asian Online Journal Publishing Group
Contribution/Acknowledgement: All authors contributed to the conception and design of the study.

Funding: This study received no specific financial support.

Competing Interests: The authors declare that they have no conflict of interests.

Transparency: The authors confirm that the manuscript is an honest, accurate, and transparent account of the study was reported; that no vital features of the study have been omitted; and that any discrepancies from the study as planned have been explained.

Ethical: This study follows all ethical practices during writing.

\section{Contents}

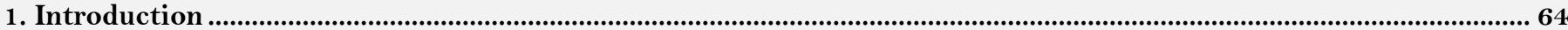

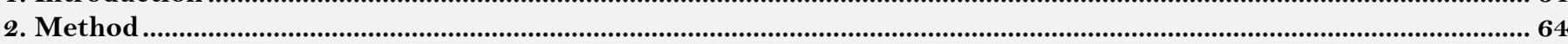

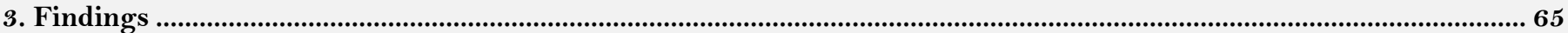

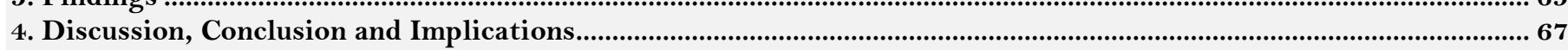

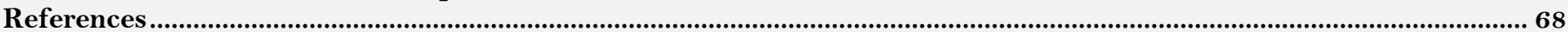




\section{Introduction}

College life is a challenging period for individuals. Students have to cope effectively with stressful situations that they meet during this challenging period. Motivational orientation, which encourages people in the face of difficulties that they encounter and helps them achieve self-regulation, is called self-efficacy (Bandura, 2001). Selfefficacy may be defined as the level of confidence that people have on their ability to perform certain types of action or achieve desired outcomes (Bandura, 1982;1997). It is a future-oriented belief related to individuals own ability which is expected to shown in a necessary situation (Bandura, 1997). In other words, self-efficacy controls one's life (Bandura, 1986).

Empirical studies have generated a several number of results that indicated the effect of self-efficacy on human functioning and behaviors (Schwarzer and Renner, 2000; Bandura, 2001). Some researchers such as Farsides and Woodfield (2003) and Duckworth et al. (2007) propounded that self-efficacy is a significant predictor of individual performance and motivation in different situations and environments. Self-efficacy is an important part of dealing with unavoidable changes in life (Bandura, 1995; Larson and Daniels, 1998). Wäschle et al. (2014) noted a vicious circle relationship between procrastination and self-efficacy. Bandura (1986) emphasized that self-efficacy strongly influences people's choices and efforts that they make while dealing with challenges. Therefore self-efficacy beliefs have an impact on task choice, effort, perseverance and success (Britner and Pajares, 2006).

According to Bandura (1997) self-efficacy beliefs may change based on some factors such as evaluation of existing abilities, perceived difficulty of action, how much effort is required, how much external support is required, past achievements, temporary patterns of success or failure and forms of reorganization of experiences. Self-efficacy is also a multidimensional construct that varies depending on domain of demands (Zimmerman, 200o) and therefore this construct must be evaluated on a level that is specific to the outcomes (Bandura, 1986; Pajares, 1996). Bandura (1997) defined the characteristics of self-efficacy as understanding, predicting, and ability to regulate the environment, the person and others. Self-efficacy beliefs differ based on the emotions, thoughts and feelings of individuals. Negative emotional experiences like stress and anxiety may have a negative impact on self-efficacy (Kelleher, 2016). People with high self-efficacy choose to perform more challenging tasks. On the other hand, low self-efficacy increases vulnerability toward depressive symptoms, anxiety and helplessness.

Highly self-efficacious people believe in their capacity to achieve specific tasks, invest more effort and have greater willingness to face challenges and solve problems rather than avoiding them (Graham, 2011). Moreover, they can set goals for themselves and spend sufficient effort to attain those goals. They are also more likely to feel confident when they face obstacles because of their belief in their ability (Pajares and Urdan, 2006). On the other hand people with low self-efficacy usually approach difficult tasks diffidently. Moreover, low self-efficacy creates a vicious cycle. People who believe they lack the skills needed to carry out a task avoid taking action which may increase self-doubt. People with low self-efficacy who are suspicious of their own abilities tend to be more easily stressed and more depressed (Rodebaugh, 2006; Luszczynska et al., 2011) and exhibit significantly more frequent risk-taking behavior (Uysal and Yilmaz-Bingol, 2014) than those with a higher self-efficacy levels. Sanna (1997) stated that people with high self-efficacy can find more alternative solutions and have more experience in performing tasks successfully than those with low self-efficacy. Individuals with high self-efficacy have positive beliefs in their capabilities to cope with stressful situations and these beliefs have significant relationship with positive emotional states that enhance resilience such as subjective well-being and life satisfaction (Salvador and Mayoral, 2011).

As mentioned above several studies demonstrated that self-efficacy is associated with adaptive psychological characteristics. Despite the plethora of research on self-efficacy and its relationship with different variables, no research has examined the relationships among self-efficacy, psychological resilience and positivity. Additionally, this study was structured to examine the predictive roles of psychological resilience and positivity on self-efficacy.

\section{Method}

\subsection{Research Design}

This current study examined the predictive roles of psychological resilience and positivity on self-efficacy. It used the general survey model.

\subsection{Study Group}

This study was conducted with a total of 844 university students enrolled at Yıldiz Technical University $(\mathrm{n}=$ 202), Ondokuz Mayıs University $(\mathrm{n}=226)$, Ankara University $(\mathrm{n}=197)$ and Uludağ University $(\mathrm{n}=219)$. The ages of the participants were between 18 and 26 years $\mathrm{M}=20.99, \mathrm{SD}=1.16)$. Of the participants, $480(56.9 \%)$ were female and $364(43.1 \%)$ were male. Table 1 presents detailed information about the participants.

It is seen in Table 1 that $56.9 \%$ of the university students participating in the research were women. $35.4 \%$ lived in the big city. $73.1 \%$ stated their income level as moderate, and $54.1 \%$ emphasized growing up with a protective family style.

\subsection{Measures}

Personal Information Form: The personal information form was prepared by the researchers to determine the demographic characteristics of the participants. 
Table-1. Demographic Characteristics of the Participants

\begin{tabular}{|c|c|c|c|}
\hline & & $\mathbf{n}$ & $\%$ \\
\hline \multirow[t]{4}{*}{ University } & Ylldız Technical University & 202 & 23.9 \\
\hline & Ondokuz Mayıs University & 226 & 26.8 \\
\hline & Ankara University & 197 & 23.3 \\
\hline & Uludağ University & 219 & 25.9 \\
\hline \multirow[t]{5}{*}{ Faculty } & Faculty of Education & 226 & 26.8 \\
\hline & Faculty of Art and Science & 218 & 25.9 \\
\hline & Faculty of Theology & 158 & 18.7 \\
\hline & Faculty of Engineering & 59 & 7.0 \\
\hline & Vocational High School & 183 & 21.7 \\
\hline \multirow[t]{4}{*}{ Grade } & First-year students & 123 & 14.6 \\
\hline & Second-year students & 278 & 32.9 \\
\hline & Third-year students & 223 & 26.4 \\
\hline & Fourth-year students & 220 & 26.1 \\
\hline \multirow[t]{2}{*}{ Gender } & Female & 480 & 56.9 \\
\hline & Male & 364 & 43.1 \\
\hline \multirow{4}{*}{ Residence } & Village-small town & 96 & 11.4 \\
\hline & District & 223 & 26.4 \\
\hline & Province & 226 & 26.8 \\
\hline & Metropolis & 299 & 35.4 \\
\hline \multirow{3}{*}{ Income Level } & Low & 51 & 6.0 \\
\hline & Average & 617 & 73.1 \\
\hline & High & 176 & 20.9 \\
\hline \multirow{4}{*}{ Parental Attitude } & Negligent & 31 & 3.7 \\
\hline & Democratic & 273 & 32.3 \\
\hline & Authoritarian & 83 & 9.8 \\
\hline & Protective & 457 & 54.1 \\
\hline Total & & 844 & 100 \\
\hline
\end{tabular}

General Self-efficacy Scale (GSES): GSES was developed by Schwarzer and Jerusalem (1995) to determine individuals' perceptions regarding their abilities to cope with difficulties, consists of 10 items and each item is scored based on a 4-point Likert-type scale (1: completely wrong, 4: completely right). The scale's Turkish validity and reliability study was carried out by Aypay (2010). The internal consistency coefficient was calculated as 0.83 for the scale. The test-retest reliability of the scale was 0.80

Brief Resilience Scale (BRS): BRS was developed by Smith et al. (2008) and focuses on the level of individual resilience. The scale consists of six items which were created in five-point Likert-type scoring format (1: strongly disagree to 5: strongly agree). The sum of all scores yields a total score that ranges from 6 to 30 ; a higher level of score indicates a higher psychological resilience. Dogan (2015) developed a Turkish adaptation of the questionnaire and reported the internal consistency coefficient of the scale as 0.83

Positivity Scale (PS): The Positivity Scale was developed by Caprara et al. (2012) in order to measure the positivity levels of individuals. The scale consists of eight items where item 6 is scored in reverse. It is a 5-point Likert-type scale ( $1=$ not at all appropriate, $5=$ very appropriate). The Turkish adaptation study of PSS had was conducted by Çıkrıkçı et al. (2015). The reliability coefficient of the Positivity Scale was found to be 0.73 . Scores on this scale could range from 8 to 40 .

\subsection{Data Collection}

The sample was determined by convenience sampling. After taking the necessary permissions from the related heads of the departments for the application of the measures, the data collection tools were applied in one session in the academic year of 2016-2017. All the participants were informed about the objectives and the process of the study by the researchers, and they participated voluntarily. It took approximately 20 minutes to complete the data collection process.

\subsection{Data Analysis}

Descriptive statistics were used to determine the self-efficacy, psychological stability and positivity levels of participants. Finally, regression analysis was used to examine the predictive roles of psychological resilience and positivity on self-efficacy. All tests had a significance level of $\mathrm{P}$ less than 0.05.

\section{Findings}

This section presents the findings and interpretations obtained as a result of statistical analysis of the data gathered in the direction of the aims covered in the research. Basic descriptive statistics for all variables of interest (Self-efficacy, psychological resilience and positivity) are presented in Table 2.

Table-2. Descriptive Statistics for Study Variables

\begin{tabular}{l|l|l|l}
\hline Variables & n & Mean & Sd \\
\hline Self-efficacy & 844 & 32.46 & 4.574 \\
\hline Psychological Resilience & 844 & 19.28 & 4.506 \\
\hline Positivity & 844 & 30.36 & 4.924 \\
\hline Source: Obtained from primary data.
\end{tabular}


The mean scores demonstrated that the sample tended to display high levels of self-efficacy $(\mathrm{M}=32.46, \mathrm{SD}=$ $4.574)$ and positivity $(\mathrm{M}=30.36, \mathrm{SD}=4.924)$. Besides, it may be stated that the mean scores of the sample exhibited a moderate level psychological resilience $(\mathrm{M}=19.28, \mathrm{SD}=4.506)$.

t- test was used for analyzing the differences between the self-efficacy scores of the male and female participants, and the results are presented in Table 3.

Table-3. Results of T- Test: Differences Between Self-efficacy Scores in Terms of Gender

\begin{tabular}{l|l|l|l|l|l|l|l}
\hline & Gender & N & Mean & S & Sd & t & p \\
\hline \multirow{2}{*}{$\begin{array}{l}\text { Self- } \\
\text { efficacy }\end{array}$} & Female & 480 & 31,98 & 4,570 &, 209 & 3,54 &, $000^{*}$ \\
\hline & Male & 364 & 33,10 & 4,508 &, 236 & & \\
\hline $\mathrm{p}<.01$
\end{tabular}

Table 3 shows that the general self-efficacy levels of the male participants were significantly higher than the women $(\mathrm{t}=3,54, \mathrm{p}<.01)$.

The results of the One-Way ANOVA Test to determine whether the general self-efficacy levels of participants differ according to their place of residence are given in Table 4 .

\begin{tabular}{|c|c|c|c|c|c|}
\hline & Sum of squares & df & Mean square & $\mathbf{F}$ & $\bar{p}$ \\
\hline Between Groups & 341,766 & 3 & 113,922 & $5,532,001$ & \\
\hline Within Groups & 17298,168 & 840 & 20,593 & & \\
\hline Total & 17639,934 & 843 & & & \\
\hline
\end{tabular}

According to the results summarized in Table 4, the self-efficacy levels of the participants were significantly different $\left[\mathrm{F}_{(3-840)}=5.53, \mathrm{p}<0.05\right]$. in terms of their place of residence. The difference between the means was determined by Bonferroni test, and it was found that the participants living in metropoles reported higher selfefficacy levels than the participants living in villages and districts.

The One-Way ANOVA Test results for determining whether the general self-efficacy levels of participants differed according to their levels of income are given in Table 5.

Table-5. Results of One-Way ANOVATest: Differences between self-efficacy scores in terms of level of income

\begin{tabular}{l|l|l|l|l|l}
\hline & Sum of squares & df & Mean square & F & $\mathbf{p}$ \\
\hline Between Groups & 175,689 & 2 & 87,845 & $4,230,01$ & \\
\hline Within Groups & 17464,244 & 841 & 20,766 & & \\
\hline Total & 17639,934 & 843 & & & \\
\hline p $<.05$
\end{tabular}

According to the results summarized in Table 5, the self-efficacy levels of the participants differ significantly $\left[\mathrm{F}_{(2-841)}=4.23, \mathrm{p}<0.05\right]$ according to their level of income. The difference between the means was determined by Dunnet test, and it was found that the participants with high income levels reported higher self-efficacy levels than the participants with average and low income levels.

The results of the One-Way ANOVA Test to determine whether the general self-efficacy levels of participants differed according to the parental attitudes they reported are given in Table 6.

\begin{tabular}{l|l|l|l|l|l|l}
\multicolumn{1}{l|}{ Table-6. Results of the One-Way ANOVA Test: Differences Between Self-efficacy Scores in Terms of Parental Attitudes } \\
\hline & Sum of squares & df & Mean square & F & p \\
\hline Between Groups & 342,637 & 3 & 114,212 & $5,546,0011$ & \\
\hline Within Groups & 17297,296 & 840 & 20,592 & & & \\
\hline Total & 17639,934 & 843 & & & & \\
\hline$p<05$ &
\end{tabular}

$\mathrm{p}<.05$

According to the results summarized in Table 6, the self-efficacy levels of the participants differed significantly $\left[\mathrm{F}_{(3-840)}=5.55, \mathrm{p}<0.05\right]$ according to their perceived parental attitudes. The difference between the means was determined by Bonferroni test and it was found that the participants who perceived their parents as authoritarian reported lower self-efficacy levels than the participants who perceived their parents as negligent, protective or democratic.

Multiple regression analyses were conducted to examine the predictive roles of psychological resilience, positivity and self-efficacy. The results are presented in Table 7.

Table-7. Multiple Regression Analyses results for self-efficacy

\begin{tabular}{l|l|l|l|l|l|l|l|l|l}
\hline $\begin{array}{l}\text { Dependent } \\
\text { Variable }\end{array}$ & $\begin{array}{l}\text { Independent } \\
\text { Variables }\end{array}$ & St. error & $\mathbf{R}$ & $\mathbf{R}^{2}$ & $\mathbf{F}$ & Binary r & Partial r & $\mathbf{t}$ \\
\hline \multirow{2}{*}{ Self-efficacy } & Psych. resilience & 0.030 & 0.577 & 0.333 & 210.087 & 0,493 & 0,425 & $13.613^{*}$ \\
\cline { 2 - 10 } & Positivity & 0.027 & 0,432 & 0,344 & $10.640^{*}$ \\
\hline
\end{tabular}

Source: Obtained from analysis of data.

According to the results of the Multiple Regression Analysis, it was found that self-efficacy was positively correlated with psychological resilience $(\mathrm{r}=0.49)$ and positivity $(\mathrm{r}=0.29)$. When psychological resilience and positivity were entered into the regression equation together, they were significantly related to self-efficacy $(\mathrm{R}=$ $0.577, \mathrm{R} 2=0.333, \mathrm{p}<0.05$ ). Psychological resilience and positivity together explained $33 \%$ of the total variance in self-efficacy. Based on results of the t-test related to the significance of regression coefficients, both variables had significant predictive roles on self-efficacy. 
It may be stated that the scattering diagram generated for the standardized value defined a linear relationship and the points tended to converge around an axis. It may be argued that the histogram and normal distribution curves generated for the standardized values showed a normal distribution. On the other hand, the scatter diagrams based on the partial relationship of the independent variables with the dependent variables showed linear and positive relationships.

\section{Discussion, Conclusion and Implications}

Self-efficacy, which is an important concept that may have an impact in different life domains, such as task choices, efforts to accomplish tasks, can be defined as people's perceptions about their capabilities to meet designated levels of performance that employ influence over events (Bandura, 1994). Enhancing self-efficacy may be helpful to solve the problems confronted by the individual because of the crucial impact of self-efficacy on performance (Yılmaz-Bingöl, 2015). Researchers and professionals can use different ways to enhance self-efficacy. One of them is to examine the relationships of different variables to self-efficacy.

The results of this study indicated that the participants reported high self-efficacy and positivity levels but moderate levels of psychological resilience. It was also found that the female participants had lower self-efficacy than the male participants and participants from a metropoles and provinces noted higher levels of self-efficacy those who are from villages or small towns. Regarding the income levels, self-efficacy scores were higher among the high-income participants in comparison to those with average and low income. Perceived parental attitudes also had an effect on the self-efficacy levels. The participants who perceived their parents as negligent, democratic and protective had higher self-efficacy than the participants who considered thinks their parents as authoritarian. Additionally, the results demonstrated that there were positive relationships between self-efficacy, psychological resilience and positivity. The results also revealed that psychological resilience and positivity were important predictors of self-efficacy.

Although some previous studies have suggested that there is link between self-efficacy levels and gender (Tiller, 1995; Ünal-Keskin and Orgun, 2006) in a study conducted by Fallan and Opstad (2016) it was aimed to examine how gender and temperament-type interactions separately affect self-efficacy. They propounded that gender is an important determinant of self-efficacy and female students have significantly lower self-efficacy levels than male students. They also showed the effect of gender-temperament interactions. Tsai and Huang (2018) research showed that self-efficacy differs based on gender. Moreover Aydiner (2011) and Cetin (2007) found that the self-efficacy levels of males were significantly higher than females. Thus, it may be stated that the results of the this study were consistent with the findings of previous studies.

Our findings were congruent with those of the research conducted by Siahpush et al. (2006) who suggested that a high-level income is related to strong self-efficacy in male participants. In their study which aimed to examine prospective teacher's levels of self-efficacy and family functions, Ikiz and Yörük (2013) reported that prospective teachers who had high levels of general self-efficacy had healthier family functions. In a study conducted with 73 male and 115 female students, Tang and Sun (2018) found that the general self-efficacy levels of male students were higher than female students. They also found that gender, residence and families income levels have effects on the family functions of prospective teachers. Thus, the findings here were in parallel with the previous studies. In the study by Dordi et al. (2011) males were often required to have higher self-confidence and self-affirmation; therefore, in a large social environment, they were given more responsibilities and studies, and then male college students constantly strived to meet the social requirements for men, which also potentially affects self-efficacy. Thus, male college students had significantly higher self-efficacy levels than female college students.

Studies (Siahpush et al., 2006) showing that low-income individuals have low self-efficacy and high-income ones have high self-efficacy support our findings. Ikiz and Yörük (2013) examined the relationship between general selfefficacy levels and family functions of prospective teachers with various variables. As a result, high-self-efficacy prospective teachers had healthier family functions, and it was affected by gender, place where most of life was spent. These results support our findings.

Researchers have suggested that self-efficacy is positively related to adaptive variables that promote psychological resilience such as self-esteem and subjective happiness (Cha, 2003; Lyubomirsky et al., 2006). Tong and Shanggui (2004) emphasized that there is a positive relationship between general self-efficacy beliefs and psychological well-being. Benight, Harding-Taylor, Midboe and Durham (2004, cited in, Akpınar (2011)) found that self-efficacy is positively related to an adaptive coping style, optimism and psychological well-being, and in contrast, negatively related to trauma-related stress and negative mood. Feldhaus et al. (2015) focused on investigating the interrelationships among the effects of loneliness, stress and self-efficacy on the life satisfaction of people with autism spectrum disorders (ASD) and their peers. They determined significant differences between the two groups and found that people with ASD reported higher loneliness, lower self-efficacy and thus lower life satisfaction, and the relationship between self-efficacy and life satisfaction was found to be stronger for individuals with ASD than for people without ASD. Self-efficacy beliefs had also a direct effect on health (O'Leary, 1992) and life satisfaction that is closely related to resilience and positivity (Çakar, 2012). People with high self-efficacy have the ability to overcome stressful situations, because these people are reported to have the attitude "I can do this" (Azar, Vasudeva, and Abdollahi 2006, cited in, Telef (2011)) thus they can be more resilient. Moreover, studies indicated that as the self-efficacy beliefs of adolescents became stronger, their risk-taking behaviors decreased (Uysal and Yilmaz-Bingol, 2014).

Magaletta and Oliver (1999) emphasized that self-efficacy and psychological well-being had a positive relationship. $\mathrm{Fu}$ et al. (2018) conducted research with 307 Chinese nurses. As a result, they found a positive relationship between self-efficacy and psychological well-being and they also expressed some elements of psychological well-being as social inclusion and self-efficacy. Tommasi et al. (2018) conducted a study with 179 Italian adolescents, and their results showed that extraversion, neuroticism, and self-efficacy beliefs in emotion regulation were correlated with psychological well-being.

Barbaranelli et al. (2018) examined in two studies whether the effect of positivity on performance is mediated by self-efficacy beliefs. The first study investigated the role of task and empathic self-efficacy in mediating the 
relationship of positivity with respect to in-role and extra-role behaviors in a sample of 829 Italian adult employees. The second on examined the role of academic self-efficacy in mediating the relationship of positivity with respect to academic grades and academic citizenship behavior in a sample of 223 Italian university students. The results of the Structural Equation Models revealed that: (1) the relationship between positivity and both in-role and extra-role behaviors was substantially mediated by self-efficacy beliefs; $(2)$ the relationship between positivity and both school grades and citizenship behaviors was completely mediated by self-efficacy beliefs. Bandura (1994) stated that selfefficacy may act as a protective factor against depression. Individuals with high self-efficacy are able to manage potential threats; otherwise they cannot control their anxiety which is a risk factor for mental health problems. Lin (2003) also found that emotional processes and self-efficacy have a relationship that allow maintaining one's goals. Similarly, Marat (2003) showed that positive emotional states may enhance self-efficacy levels. Byrne (2002) stated that individuals with low levels of self-efficacy reported more depression, anxiety, and helplessness. These findings are congruent with our findings.

This study has some limitations. The data used here on self-efficacy, psychological resilience, positivity and demographic information based on self-reports. Thus, future research may gather data using different methods like interviews with parents or teachers and peer reports may be useful. Additionally, all the participants were university students from Turkey in this study. Similar studies should be conducted on other student populations.

In conclusion, this study showed that psychological resilience and positivity affect self-efficacy directly, and demographic variables powerfully influence self-efficacy beliefs. These current findings increase our understanding of the relationships between self-efficacy and related variables. Moreover, the data reported here were gathered from four different cities in Turkey. So, the results are important because of the comprehensive participation. Additionally, professionals working with university students may develop programs to enhance resilience and positivity and to increase levels of self-efficacy, which is a significant construct for setting goals and achieving them. These programs also contribute to the literature on self-efficacy. Efforts to develop self-efficacy beliefs, a fundamental concept in determining and attaining individual life goals, will primarily contribute to a better life span of individuals, while at the same time expanding the field literature.

\section{References}

Akpinar, O., 2011. The prediction of levels of domestic violence coping self efficacy of women who were victimized by domestic violence according to some variables. Unpublished Doctorate Dissertation. Ege University, İzmir.

Aydiner, B.B., 2011. The relationship between sub-dimensions of the life goals with general self-efficacy, life-satisfaction and some variables. Unpublished Master's Thesis, Sakarya University, Sakarya.

Aypay, A., 2010. The adaptation study of general self-efficacy (Gse) scale to Turkish. Inonu University Journal of the Faculty of Education, $11(2): 113-131$.

Bandura, A., 1982;1997. Self-efficacy mechanism in human agency. American Psychologist, 37(2): 122-147. Available at: https://doi.org/10.1037//0003-066x.37.2.122.

Bandura, A., 1986. Social foundations of thought and action: A social cognitive theory. Englewood Cliffs, NJ: Prentice-Hall.

Bandura, A., 1994. Self-efficacy. In. VS Ramachaudran. Encyclopedia of Human Behavior, 4(4): 71-81.

Bandura, A., 1995. Exercise of personal and collective self-efficacy in changing societies. In A. Bandura (Ed.), Self-efficacy in changing societies. New York: Cambridge University Press. pp: 1-45.

Bandura, A., 1997. Self-efficacy: The exercise of control. New York: W. H. Freeman and Company.

Bandura, A., 2001. Social cognitive theory: An agentic perspective. Annual Review of Psychology, 52(1): 1-26. Available at: https://doi.org/10.1 146/annurev.psych.52.1.1.

Barbaranelli, C., M. Paciello, V. Biagioli, R. Fida and C. Tramontano, 2018. Positivity and behaviour: The mediating role of self-efficacy in organisational and educational settings. Journal of Happiness Studies: 1-12. Available at: https://doi.org/10.1007/s 10902-018$9972-4$.

Britner, S.L. and F. Pajares, 2006. Sources of science self-efficacy beliefs of middle school students. Journal of Research in Science Teaching, 43(5): 485-499. Available at: https://doi.org/10.1002/tea.20131.

Byrne, B., 2002. Relationships between anxiety, fear, self-esteem, and coping strategies in adolescence. Adolescence, 35(136): $201-215$.

Çakar, F.S., 2012. The relationship between the self-efficacy and life satisfaction of young adults. International Education Studies, 5(6): 123130. Available at: ttps://doi.org/10.5539/ies.v5n6p123.

Caprara, G.V., G. Alessandri, N. Eisenberg, A. Kupfer, P. Steca, M.G. Caprara, S. Yamaguchi, A. Fukuzawa and J. Abela, 2012. The positivity scale. Psychological Assessment, 24(3): 701-712.

Cetin, B., 2007. The effects of new primary educational curricula applications (2005) on the 4th and 5th grade elementary students' habits of studying and their self-efficacy level, and the opinions of those students about the new curricula. Unpublished Doctorate Dissertation, Marmara University, İstanbul.

Cha, K.-H., 2003. Subjective well-being among college students. Social Indicators Research, 62/63(1-3): 455-477. Available at: https://doi.org/10.1023/a:1022669906470.

Çıkrıkçı, Ö., M. Çiftçi and B. Gençdoğan, 2015. The psychometric properties of the Turkish form of the positivity scale. The Journal of Happiness and Well-Being, 3(1): 57-76.

Dogan, T., 2015. Turkish adaptation of the short psychological resilience scale: Validity and reliability study. The Journal of Happiness \& Well-Being, 3(1): 93-102.

Dordi, N., Farhad Ghorban, H. Hakimi, M. Ashouri, M. Dehghani, Z. Zeinali, M.S. Daghighi and N. Bahrami, 2011. On the relationship between test anxiety and academic performance. Procedia-Social and Behavioral Sciences, 15: 3774-3778.

Duckworth, A.L., C. Peterson, M.D. Matthews and D.R. Kelly, 2007. Grit: Perseverance and passion for long-term goals. Journal of Personality and Social Psychology, 92(6): 1087-1101. Available at: https://doi.org/10.1037/0022-3514.92.6.1087.

Fallan, L. and L. Opstad, 2016. Student self-efficacy and gender-personality interactions. International Journal of Higher Education, 5(3): 3244. Available at: https://doi.org/10.5430/ijhe.v5n3p32.

Farsides, T. and R. Woodfield, 2003. Individual differences and undergraduate academic success: The roles of personality, intelligence, and application. Personality and Individual Differences, 34(7): 1225-1243. Available at: https://doi.org/10.1016/s0191-8869(02)001113.

Feldhaus, C., U. Koglin, J. Devermann, H. Logemann and A. Lorenz, 2015. Students with autism spectrum disorders and their neuro-typical peers - differences and influences of loneliness, stress and self-efficacy on life satisfaction. Universal Journal of Educational Research, 3(6): 375-381. Available at: https://doi.org/10.13189/ujer.2015.030604.

Fu, F., Y. Liang, Y. An and F. Zhao, 2018. Self-efficacy and psychological well-being of nursing home residents in China: The mediating role of social engagement. Asia Pacific Journal of Social Work and Development, 28(2): 128-140. Available at: https://doi.org/10.1080/02 185385.2018.1464942.

Graham, S., 2011. Self-efficacy and academic listening. Journal of English for Academic Purposes, 10(2): 113-117. Available at: https://doi.org/10.1016/j.jeap.2011.04.001.

Ikiz, F.E. and C. Yörük, 2013. The investigation of self-efficacy levels and family functions of teacher trainees. Usak University Journal of Social Science, 6(1): 228-248.

Kelleher, J., 2016. You're ok, i'm ok. Delta Kappan, 97(8): 70-73. 
Larson, L.M. and J.A. Daniels, 1998. Review of the counseling self-efficacy literature. The Counseling Psychologist, 26(2): 179-218. Available at: https://doi.org/10.1177/0011000098262001.

Lin, C.H., 2003. Intergenerational parallelism of self-efficacy: Moderating variables, mediating variables, and common antecedents. Unpublished Doctoral Dissertation.

Luszczynska, A., R. Schwarzer, S. Lippke and M. Mazurkiewicz, 2011. Self-efficacy as a moderator of the planning-behaviour relationship in interventions designed to promote physical activity. Psychology and Health, 26(2): 151-166. Available at: https://doi.org/10.1080/08870446.2011.531571.

Lyubomirsky, S., C. Tkach and M.R. DiMatteo, 2006. What are the differences between happiness and self-esteem. Social Indicators Research, 78(3): 363-404. Available at: https://doi.org/10.1007/s11205-005-0213-y.

Magaletta, P.R. and J. Oliver, 1999. The hope construct, will, and ways: Their relations with self-efficacy, optimism, and general well-being. Journal of Clinical Psychology, 55(5): 539-551. Available at: https://doi.org/10.1002/(sici) 1097-4679(199905)55:5<539::aidjclp2>3.3.co;2-7.

Marat, D., 2003. Assessing self-efficacy and agency of secondary school students in a multi-cultural context: Implications for academic achievement proceeding of the New Zealand and Australian. Association for Research in Education Conference, Auckland.

O'Leary, A., 1992. Self-efficacy and health: Behavioral and stress-physiological mediation. Cognitive Therapy and Research, 16(2): 229-245. Available at: https://doi.org/10.1007/bfo1 173490.

Pajares, F., 1996. Self-efficacy beliefs in academic settings. Review of Educational Research, 66(4): 543-578. Available at: https://doi.org/10.2307/1170653.

Pajares, F. and T. Urdan, 2006. Adolescence and education, self-efficacy beliefs of adolescents. Greenwich, CT: Information Age Publishing.

Rodebaugh, T.L., 2006. Self-efficacy and social behavior. Behaviour Research and Therapy, 44(12): 1831-1838.

Salvador, C. and L. Mayoral, 2011. Entrepreneurial self-efficacy and life satisfaction in the ICT sector: A study of gender differences in Argentina. Journal of Basic and Applied Scientific Research, 1(3): 242-251.

Sanna, L.J., 1997. Self-efficacy and counterfactual thinking: Up to a creek with or without a paddle. Personality and Social Psychology Bulletin, 23(6): 654-667. Available at: http://dx.doi.org/10.1177/014616729723600.

Schwarzer, R. and M. Jerusalem, 1995. Optimistic self-beliefs as a resource factor in coping with stress. In Extreme stress and communities: Impact and intervention. Dordrecht: Springer. pp: 159-177.

Schwarzer, R. and B. Renner, 2000. Social-cognitive predictors of health behavior: Action self-efficacy and coping self-efficacy. Health Psychology, 19(5): 487-495. Available at: https://doi.org/10.1037//0278-6133.19.5.487.

Siahpush, M., A. McNeill, R. Borland and G. Fong, 2006. Socioeconomic variations in nicotine dependence, self-efficacy, and intention to quit across four countries: Findings from the international tobacco control (ITC) four country survey. Tob Control, 15(suppl_3): iiiz1iii 75. Available at: https://doi.org/10.1136/tc.2004.008763.

Smith, B.W., J. Dalen, K. Wiggins, E. Tooley, P. Christopher and J. Bernard, 2008. The brief resilience scale: Assessing the ability to bounce back. International Journal of Behavioral Medicine, 15(3): 194-200. Available at: https://doi.org/10.1080/10705500802222972.

Tang, J. and Q. Sun, 2018. Research on general self-efficacy and test anxiety of normal university students. World Journal of Educational Research, 5(2): 191-197. Available at: https://doi.org/10.22158/wjer.v5n2p191.

Telef, B.B., 2011. The study of teachers' self-efficacy, job satisfaction, life satisfaction and burnout. Elementary Education Online, 10(1): $91-$ 108.

Tiller, D., 1995. Self-efficacy in college students. Missouri Western State College. Retrieved from http://www.psych.mwsc.edu/research/psy302/fall95/tiller.html Ward, CD (2001). Students' attitudes and achievement as related to immediate remediation in paced algebra. $\mathrm{PhD}$.

Tommasi, M., P. Grassi, M. Balsamo, L. Picconi, A. Furnham and A. Saggino, 2018. Correlations between personality, affective and filial selfefficacy beliefs, and psychological well-being in a sample of Italian adolescents. Psychological Reports, 12 1(1): 59-78. Available at: https://doi.org/10.1177/0033294117720698.

Tong, Y. and S. Shanggui, 2004. A study on general self-efficacy and subjective well-being of low SES college students in a Chinese university. College Students Journal, 38(4): 637-642.

Tsai, C.Y. and T.C. Huang, 2018. The relationship between adult self-efficacy and scientific competencies: The moderating effect of gender. International Journal of Science and Mathematics Education, 16(1): 91-106. Available at: https://doi.org/10.1007/s10763-0179869-4.

Ünal-Keskin, G. and F. Orgun, 2006. Examination of strategies to cope with self efficacy-competence levels of students. Anatolian Journal of Psychiatry, 7(2): 92-99.

Uysal, R. and T. Yilmaz-Bingol, 2014. Examining adolescents. Journal of Academic Social Research, 2(8): 573-582.

Wäschle, K., A. Allgaier, A. Lachner, S. Fink and M. Nückles, 2014. Procrastination and self-efficacy: Tracing vicious and virtuous circles in self-regulated learning. Learning and Instruction, 29: 103-1 14. Available at: https://doi.org/10.1016/j.learninstruc.2013.09.005.

Yllmaz-Bingöl, T., 2015. The effect of solution focused brief approach based group guidance programme on self - efficacy beliefs. Unpublished Doctorate Dissertation, Sakarya University, Sakarya.

Zimmerman, B.J., 2000. Self-efficacy: An essential motive to learn. Contemporary Educational Psychology, 25(1): 82-91. Available at: https://doi.org/10.1006/ceps.1999.1016. 